This is the author's final, peer-reviewed manuscript as accepted for publication. The publisher-formatted version may be available through the publisher's web site or your institution's library.

\title{
Attitudes toward dating violence among college students in mainland China: an exploratory study
}

Jared R. Anderson, Wen Chi Chen, Matthew D. Johnson, Sarah E. Lyon, Chih-Yuan Steven Lee, Fuming Zheng, Gary C. Ratcliffe, F. Ryan Peterson

\section{How to cite this manuscript}

If you make reference to this version of the manuscript, use the following information:

Anderson, J. R., Chen, W. C., Johnson, M. D., Lyon, S. E., Lee, C.-Y. S., Zheng, F., ... Peterson, F. R. (2011). Attitudes toward dating violence among college students in mainland China: An exploratory study. Retrieved from http://krex.ksu.edu

\section{Published Version Information}

Citation: Anderson, J. R., Chen, W. C., Johnson, M. D., Lyon, S. E., Lee, C.-Y. S., Zheng, F., ... Peterson, F. R. (2011). Attitudes toward dating violence among college students in mainland China: An exploratory study. Violence and Victims, 26(5), 631-647.

Copyright: ( 2011 Springer Publishing Company

Digital Object Identifier (DOI): doi:10.1891/0886-6708.26.5.631

Publisher's Link: http://dx.doi.org/10.1891/0886-6708.26.5.631

This item was retrieved from the K-State Research Exchange (K-REx), the institutional repository of Kansas State University. K-REx is available at http://krex.ksu.edu 
Running head: DATING VIOLENCE ATTITUDES

Attitudes Toward Dating Violence among College Students in Mainland China: An Exploratory Study

Jared R. Anderson, Ph.D., Wen Chi Chen, M.S., Matthew D. Johnson, M.S., Sarah E. Lyon, M.S. Kansas State University

Chih-Yuan Steven Lee, Ph.D., Montclair State University

Fuming Zheng, Ph.D. South China Normal University, China PRC

Gary C. Ratcliffe, B.A.

Kansas State University

F. Ryan Peterson, Ph.D.

University of Central Missouri

Address Correspondence to: Jared R. Anderson, Ph.D., Kansas State University, School of Family Studies and Human Services, 209 Campus Creek Complex, Manhattan, KS 66506 (jra@ksu.edu) 


\begin{abstract}
This study investigates attitudes toward psychological and physical dating violence among college students in Mainland China $(N=245)$. The results of this study indicate that among our sample of college students in Mainland China, men and women were relatively similar in their attitudes towards male perpetrated and female perpetrated physical dating violence and female perpetrated psychological dating violence. As has been found in previous research, men and women in our sample were more accepting of female perpetrated physical and psychological dating violence than male perpetrated physical and psychological dating violence. Finally, among several variables that predicted dating violence attitudes, shame emerged as a potentially important variable to include in future studies on dating violence in Chinese populations.
\end{abstract}

Key Words: China, College Students, Dating Violence, Predictors, Shame 
Dating violence is a worldwide phenomenon that has significant mental and physical health ramifications for those involved. Studies show that there are relatively high rates of physical assault (30-34\%) and psychological aggression (93-98\%) between dating partners in the United States (Riggs \& O’Leary, 1996), as well as high rates of sexual coercion (27.8\%), physical assault (22.3\%) and psychological aggression (79.1\%) reported by college women in Canada (DeKeseredy \& Kelly, 1993). Though the literature on dating violence comes predominantly from North American samples, one notable exception is the international dating violence study. This study gathered data from 31 universities worldwide and found prevalence rates for physical assault ranging from $17 \%$ to $45 \%$ within dating relationships (Straus, 2004).

In addition to its worldwide prevalence, dating violence is also associated with a host of negative outcomes. These include increased risk of sexually transmitted diseases, chronic or temporary health problems, posttraumatic stress disorder, somatic complaints, anxiety, fear, anger (Amar \& Gennero, 2005), depression (Banyard \& Cross, 2008), lowered self-worth (O’Leary \& Cascardi, 1998); decreased satisfaction with relationship and life, and greater levels of life disruption than those who do not experience dating violence (Amar \& Alexy, 2005). Given the prevalence of dating violence and the negative physical and psychological health outcomes associated with being in a violent dating relationship, there has been an increased focus in the literature on understanding dating violence and the factors that predict dating violence. This study attempts to add to this growing body of literature by focusing on dating violence attitudes, a known predictor of dating violence, in an understudied population, college students in Mainland China.

\section{Dating Violence in China}

The international dating violence study provides the clearest descriptive picture of 
physical dating violence in Mainland China, with approximately 35\% of college student dating relationships reporting some form of physical assault (Straus, 2008). Data from this project also indicates that women perpetrate dating violence significantly more frequently than men in China (Chan, Straus, Brownridge, Tiwari, \& Leung, 2008; Straus, 2008). A qualitative study of Chinese women's aggression in dating relationships suggests that women's use of violence is perceived as normative behavior by both men and women (Wang \& Sik Ying Ho, 2007). While there is some descriptive information about dating violence in Mainland China, the extant empirical literature provides very limited information about the factors that lead over one third of Mainland Chinese young adults to engage in dating violence. Partner dominance (Straus, 2008), depression, suicidal ideation, and self-harming (Chan et al., 2008) behaviors have all emerged as correlates of dating violence in samples that included college students from Mainland China. However, there is yet to be empirical studies of factors associated with dating violence in a sample comprised solely of Mainland Chinese young adults in dating relationships. One study did investigate predictors of dating violence in college students from Hong Kong (Chan, Tiwari, Leung, Ho, \& Cerulli, 2007), a population that may be culturally similar to students in mainland China. Chan et al. (2007) reported that personality factors, criminal history, gender hostility, PTSD symptomatology, violence approval, anger management, problematic communication, jealousy, negative attribution, and demographic factors (age and relationship length) were associated with an increased likelihood of physical assault perpetration in dating relationships.

\section{Attitudes Toward Dating Violence}

Attitudes toward dating violence has emerged in the broader dating violence literature as a significant predictor of actual dating violence perpetration. An individual's attitude toward both male perpetrated and female perpetrated dating violence influences the likelihood of that 
individual becoming involved in a violent dating relationship in the present (Medeiros \& Straus, 2004; O'Keefe, 1997; Bookwala, Frieze, Smith, \& Ryan, 1992). Partners who hold attitudes that endorse dating violence are more likely to have been abusive in their relationships (Bookwala et al., 1992; O'Keefe, 1997) and to perpetrate dating violence later in life, particularly for males (Foshee et al., 2001). Data on females' attitudes toward dating violence in relation to actual perpetration is more limited compared to studies on males. Initial findings reveal that traditional sex-role beliefs, increased feelings of romantic jealousy, and higher levels of interpersonal and verbal aggression in the past were found to predict expressed violence among females (Bookwala et al., 1992). Positive attitudes toward male and female perpetrated dating violence have also been linked with greater acceptance of the use of violence outside of dating relationships (Josephson \& Prouix, 2008). Due to this connection between accepting attitudes toward dating violence and the actual perpetration of violence, dating violence prevention programs have been developed for college students that target dating violence attitudes as a way to reduce actual perpetration (Schwartz, Griffin, Russell, \& Frontaura-Duck, 2006). It has been noted that culture plays a formative role in shaping attitudes toward violence (Flood \& Pease, 2009) and research on this topic is extremely limited in Mainland China. Preliminary evidence indicates that positive attitudes toward rape are linked to sexual violence among Chinese students (Chan, 2009) and Chan et al. (2007) found violence approval to be a significant predictor of physical dating violence perpetration among college students in Hong Kong. However, in the Chan et al. (2007) study, violence approval referred to the use of violence in a variety of interpersonal situations (disciplining children and men getting into physical fights with other men), not between partners in a dating relationship. To date, the specific attitudes that 
Mainland Chinese college students hold toward psychological and physical dating violence perpetration has yet to be explored.

\section{Predictors of Attitudes Toward Dating Violence \& Dating Violence}

Although attitudes toward dating violence is a known predictor of dating violence, there are few studies that attempt to determine the factors related to attitudes toward dating violence. In their study of college students, Nabors, Dietz, and Jasinski (2006) found that men and students that were not as far along in their university education held beliefs that were more supportive of physical and sexual abuse in relationships. Nabors et al. also found that Hispanic participants and participants that marked their racial or ethnic category as "other" were least likely to hold attitudes that were accepting of verbal abuse. These predictors accounted for only $3.8 \%$ and $1.7 \%$ of the variance in attitudes towards physical/sexual abuse and verbal abuse, respectively. Several variables including father's education, mother's education, family income, parents' marital status, and relationship status were not significantly related to college student's attitudes towards physical, sexual, and verbal abuse. In sum, few sociodemographic factors significantly predicted attitudes towards violence and those that did, were relatively weak predictors. Price, Byers et al. (1999) found that traditional gender role attitudes, previous perpetration in a dating relationship, and aggressive friends (for boys) were associated with more accepting attitudes toward some forms of dating violence for high school students. Finally, previous research has found that both male and female college students are more accepting of female physical (Bethke \& DeJoy, 1993; Price et al., 1999) and psychological (Price et al.) dating violence than male physical and psychological dating violence.

Compared to the research on predictors of dating violence attitudes, much effort has been directed at finding predictors and antecedents of dating violence behavior, with the hope of 
shedding light on intervention and prevention. As mentioned above, attitudes toward dating violence has been found to be a strong predictor of the actual act. Several other variables have been found to significantly predict physical assault and psychological aggression. These predictors include alcohol use (Luthra \& Gidycz, 2006; Murray \& Kardatzke, 2007; Lewis \& Fremouw, 2001), especially early alcohol consumption at a young age (Chen \& White, 2004); drug abuse (Chase, Treboux, \& O’Leary, 2002); witnessing parental violence (Chen \& White, 2004), with a possibility that this is a stronger predictor for males than females (Lewis \& Fremouw, 2001); increased relationship length (Luthra \& Gidycz, 2006); increased negativity in the relationship (Marcus \& Swett, 2002); past dating violence victimization (Baker \& Stith, 2008); depression (Chase, Treboux, \& O’Leary, 2002); and being academically at-risk at school, such as having poor school performance (O’Keefe, 1998). In addition, a variety of studies have shown that acceptance of more traditional gender roles tends to be a predisposing factor towards more acceptance (Davis \& Liddell, 2002) and increased acts of dating violence in the United States (Parrot \& Zeichner, 2003; Reidy, Shirk, Sloan, \& Zeichner, 2009).

Finally, shame, although not often studied in the context of dating violence has particular salience in understanding Chinese cultural and social context (Bedford, 2004; Qian, 2007). Shame is a negative emotion directed at one's sense of self (Tangney, 1995) and involves feeling inferior to others, a desire to conceal inequities, and a keen awareness of negative evaluation (real or imagined) from others (Tangney, Miller, Flicker, \& Barlow, 1996). Shame is related to the perception and fear of "others" rejecting "self” (Pettit et al., 2002). Upholding one's place or identity in the social hierarchy is looked upon as one's duty in Chinese culture (Hwang, 2001), therefore, failure to uphold social norms through inappropriate behavior can result in "losing face" and causing shame to one's family (Lester, 1997). Lewis (1971) contends that shame is 
initially directed at self but then often turns into anger and hostility toward others, specifically, toward those deemed responsible for contributing to the individual's feelings of shame. There is evidence that hostility that follows shame is often used as a defense mechanism to help channel angry feelings outward and that individuals who are prone to shame are also prone to exhibiting hostility and anger and are more likely to choose maladaptive and unconstructive interpersonal responses, such as physical and verbal aggression (Tangney, 1995; Wiginton et al. 2004). In the only study to date utilizing shame as a predictor of dating violence, Harper, Austin, Cercone, and Arias (2005) found that anger mediated the relationship between perceived levels of shame in men and their perpetration of psychological abuse. The link between shame and dating violence attitudes has not been studied. Given the importance of shame in Chinese culture and the link between shame, anger, and hostility, it is plausible that shame could be a predictor of dating violence attitudes among Mainland Chinese college students.

Purpose of the Research - An Exploratory Study

This study builds on recent research regarding dating violence beliefs and attitudes of U.S. college students (Nabors et al., 2006; Price et al., 1999) by examining these beliefs and attitudes among Mainland Chinese college students, a population not extensively studied in the context of dating violence. The purpose of this study is to take an initial, exploratory look at dating violence attitudes among Chinese college students. The current study represents a clear extension of the current literature by investigating the relationship of Mainland Chinese college students' dating violence attitudes and a culturally salient variable (shame), variables previously shown to be significant in the literature (role hierarchy, depression, and year at the university) (Byers et al., 1999; Chan et al., 2008; Nabors et al., 2006), and exploratory variables (views on nonmarital cohabitation and family income). A greater understanding of the variables that predict dating 
violence attitudes among this population will be of significance to clinicians and educators, who will be able to create interventions or educational programs that address positive attitudes toward dating violence before young people engage in violent behaviors in their partnerships. Therefore, this study will address the following research questions:

1. Do male and female Mainland Chinese college students differ in their attitudes toward dating violence?

2. Do Mainland Chinese college students have more accepting attitudes of psychological and physical dating violence when perpetrated by women than when perpetrated by men?

3. How do various demographic, attitudinal, and personal well-being variables predict attitudes toward male and female dating violence in Mainland Chinese college students?

Method

\section{Procedures}

This study is part of a larger project developed by a team of researchers to investigate the mental and physical health, family formation attitudes, and dating violence attitudes of college students in China. The original survey included 227-items and each item was translated from English to Mandarin by a native speaker of Mandarin and then back-translated from Mandarin to English by a separate native Mandarin speaker in order to retain the measures' original meanings. The individuals who completed the translation and back translation both completed their Ph.D. in Family Studies in the U.S. The survey was distributed to 300 undergraduate students at a Mainland Chinese university. The students were requested to return the survey within one week.

\section{Participants}


The participants were 245 undergraduate students attending a Mainland Chinese university. Females comprised $77.7 \%$ of the sample, and males comprised $22.3 \%$ of the sample. The average age of the participants was 21 years old $(S D=1.0)$, and nearly three-fourths of the participants were between the ages of 18 and 21 . The majority of the sample consisted of first $(30.2 \%)$ and second (36.3\%) year students while the remaining one-third of participants identified themselves as third year students. Most students (88.5\%) reported that their parents were currently married. At the time of the study, approximately half of the participants were not currently in a dating relationship and nearly $40 \%$ indicated that they had never been in a relationship lasting longer than one month. However, of those students who were currently in a dating relationship at the time of the study, $15.4 \%$ specified that they were in a casual dating relationship, while $33.7 \%$ were in serious, committed relationships. The average length, in months, of the participants' relationships was 22.6 months $(S D=18.5)$.

\section{Measures}

Attitudes Toward Dating Violence Scales. Participants completed four scales that measured attitudes toward dating violence in both males and females: the Attitudes Toward Male Psychological Dating Violence Scale (e.g., A guy should not insult his girlfriend; 15 items), the Attitudes Toward Female Psychological Dating Violence Scale (e.g., There is no excuse for a girl to threaten her boyfriend; 13 items), the Attitudes Toward Male Physical Dating Violence Scale (e.g., It is O.K. for a guy to slap his girlfriend if she deserves it; 12 items), and the Attitudes Toward Female Physical Dating Violence Scale (e.g., A girl should not hit her boyfriend regardless of what he has done; 12 items) (Price et al., 1999). Responses range from "strongly disagree" (1) to "strongly agree" (5). Higher scores indicate more positive attitudes 
toward dating violence. Cronbach's alpha coefficients in the current study for the four subscales ranged from .64 to .74 .

The Experience of Shame Scale (ESS). The Experience of Shame Scale (25 items) was also administered in this study (Andrews et al., 2002). The ESS measures 3 areas of shame: characterological shame, behavioral shame, and bodily shame. Characterological shame includes shame of personal habits, manner with others, sort of person you are, and personal ability (e.g., Have you felt ashamed of any of your personal habits?). Behavioral shame encompasses shame about doing something wrong, saying something stupid, and failure in competitive situations (e.g., Have you tried to cover up or conceal things you felt ashamed of having done?). Bodily shame refers to feeling ashamed of your body or any part of your body (e.g., Have you worried about what other people think of your appearance?). Each area covered in the ESS contains questions aimed at assessing the experiential, cognitive, and behavioral components of that area. Responses range from "not at all" (1) to "very much" (4), with a higher score indicating a greater amount of shame. The ESS is contained in a larger scale, The Shame Scale, which was developed in China and psychometrically validated using Chinese college students (Qian, Andrews, Zhu, \& Wang, 2000). For the current study, we used the total shame score which had a Cronbach's alpha coefficient of .92.

Marital Meanings Inventory Subscale - Role Hierarchy (MMI-RH). The MMI is a scale designed to assess the various meanings that the institution of marriage tends to hold for people (Hall, 2006). MMI-RH is composed of three questions and focuses on role hierarchy (e. g., "Husbands should have the final say when there are disagreements about the family." "In an ideal marriage, man is the achiever outside, women takes care of the home.”). Responses range from "not true at all (1)" to "very true (5)" and yield a total subscale score of 3-15 with higher 
scores indicating a stronger belief in traditional gender role hierarchy. Cronbach's alpha coefficient in the current study for this scale is .53. Given that the alpha coefficient is, in part, a result of the number of items in the scale, the reliability of this scale was reasonable for a short, survey-based instrument (Carmines \& Zeller, 1979).

Patient Health Questionnaire-9 (PHQ-9). Each of the items on the PHQ-9 corresponds directly to each of the diagnostic criteria for major depressive disorder, as identified by the DSMIV-TR (Kroenke, Spitzer, \& Williams, 2001). Example questions are "Over the last two weeks, how often have you been bothered by any of the following problems? Little interest or pleasure in doing things; feeling down, depressed, or hopeless; feeling tired or having little energy," etc. Responses range from "not at all" (0) to "nearly every day" (3). Kroenke et al. report internal consistency for this measure to range from .86 to .89 . In addition, construct validity has been established by comparing the PHQ-9 responses to the SF-20, disability days, symptom-related difficulty, and trips to the doctor. The Cronbach's alpha coefficient for the current study is .84 .

Non-Marital Cohabitation Views. This 6-item scale asks a variety of questions aimed at determining the respondent's acceptance of non-marital cohabitation. Items for the scale include "It is all right for a couple to live together without planning to get married," and "Living together first is a good way of testing how workable a couple's marriage would be.” Responses for all items range from "strongly disagree" (1) to "strongly agree" (4) and higher scores indicate greater acceptance of non-marital cohabitation. Cronbach's alpha is .86 in the current study.

Family Income and Year at the University. Family income was measured by a single open-ended question asking participants, "What is the average monthly income for your family?" Results were converted to U.S. dollars. Year at the university was measured by a single question 
asking participants, "What is your year at the university." Responses ranged from freshman to graduate student.

\section{Data Analysis Plan}

Data analyses were conducted in three phases. First, correlations were computed to determine whether a number of predictor variables were associated with attitudes toward male and female perpetrated physical and psychological dating violence. Second, to explore gender differences on both the independent and dependent variables a one-way ANOVA was computed. Third, a paired-samples t-test was computed to determine whether students had more accepting attitudes of psychological and physical dating violence when perpetrated by women than when perpetrated by men. Finally, multiple regression analyses were used to determine the variables that predicted attitudes toward dating violence.

\section{Results}

Given the exploratory nature of this study, we included a number of potential demographic, attitudinal, and personal well-being variables in the correlation analysis. The demographic variables included age, gender, relationship length, relationship history, family income, parental marital quality and current year at university. The attitudinal variables included role hierarchy (traditional gender role attitudes), satisfaction with school performance, and endorsement of cohabitation. Finally, the personal well-being variables included shame, depression, hopelessness, life satisfaction, and physical health. Only the six variables that were significantly correlated with one or more of the dating violence attitude measures were included in the regression analyses. An overview of these six predictor variables is provided in the "measures" section above. They include the demographic variables of current year at university and family income, the attitudinal variables of role hierarchy (traditional gender role attitudes), 
endorsement of cohabitation, and the personal well-being variables of shame and depression.

Table 1 provides zero-order correlations of the six independent predictor variables and the four dependent variables. [Insert Table 1]

The results of the one-way ANOVA comparing the mean differences between men and women on all four attitude toward dating violence variables and all six predictor variables showed few statistically significant differences between men and women (See Table 2). Results indicate that significant differences exist between men and women on attitudes toward male psychological dating violence $(F=5.020, p<.05)$, but not on attitudes toward the other three dating violence scales. On average, males scored significantly higher on attitudes toward the use of male psychological dating violence than females scored (males: $M=38.71, S D=6.17$, females: $M=36.24, S D=7.13$ ), meaning that males were more accepting of male perpetration of psychological violence toward their female partners than females were. These overall scores suggest that in this sample, males and females generally do not differ on their views of dating violence. Similarly, few differences on the predictor variables were found between men and women. The only predictor variable where men and women differed significantly was role hierarchy $(F=15.43, p<.001)$, where men were found to have more traditional attitudes toward gender roles than women. [Insert Table 2]

On average, Mainland Chinese college students had attitudinal scores that reflected greater acceptance toward the use of female perpetrated physical $(M=2.81 S D=.60)$ and psychological $(M=2.58 S D=.52)$ abuse than they had on attitudes toward male perpetrated physical $(M=2.52 S D=.58)$ and psychological $(M=2.46 S D=.47)$ abuse. Because the attitudes toward dating violence scales (e.g., male psychological, female psychological) had different numbers of questions associated with them, the mean score rather than the total score was used 
in the analyses. A dependent samples t-test was computed to determine whether Mainland Chinese college students had more accepting attitudes of psychological and physical dating violence when perpetrated by women than when perpetrated by men. Results of the $t$-test indicate that Mainland Chinese college students do have more accepting attitudes toward both psychological, $t(233)=3.50, p<.001$, and physical, $t(229)=7.45, p<.001$, dating violence when perpetrated by women than when perpetrated by men.

Finally, multiple regression analyses were performed to identify the variable(s) most predictive of attitudes toward male and female perpetrated physical and psychological dating violence. Given the exploratory nature of this study and the fact that men and women were not found to significantly differ on five of the six predictor variables utilized in this study, the total sample was used when predicting attitudes toward male and female physical violence and female psychological violence. Separate regression analyses were conducted for men and women when predicting attitudes toward male psychological violence. Therefore, a total of five separate regression analyses were conducted. Again, given the exploratory nature of this study, we utilized a fully saturated model that included the following independent variables: shame, depression, role hierarchy, current year at university, family income, and endorsement of cohabitation. Attitudes toward male and female physical and psychological dating violence were entered as the dependent variables.

Attitudes toward female dating violence. Shame, endorsement of cohabitation, and family income were predictive of attitudes toward female perpetrated physical dating violence, $F=$ $2.466, p<.05$, explaining approximately $7.4 \%$ of the variance. Therefore, Mainland Chinese college students in our sample who had higher levels of shame, more positive attitudes toward cohabitation, and were from families with lower incomes were more likely to endorse more 
positive attitudes toward female use of physical dating violence. Shame and current year at university were predictive of attitudes toward female perpetrated psychological dating violence, $F=4.432, p<.001$, explaining approximately $12.4 \%$ of the variance. In other words, Mainland Chinese college students in our sample who had higher levels of shame and who had been in college longer were more likely to endorse more positive attitudes toward females' use of psychological dating violence. See Table 3. [Insert Table 3]

Attitudes toward male dating violence. Shame and current year at university were predictive of attitudes towards male perpetrated physical dating violence, $F=3.715, p<.05$, explaining approximately $7.9 \%$ of the variance. In other words, Mainland Chinese college students in our sample who had higher levels of shame and who had been in college longer were more likely to endorse more positive attitudes toward males' use of psychological dating violence. Given that men and women significantly differed in their attitudes toward male psychological dating violence, separate regression analyses were run for men and women. For women, role hierarchy was the only significant variable that predicted women's attitudes toward male perpetrated psychological dating violence, $F=2.176, p<.05$, explaining approximately $8.6 \%$ of the variance. Women who were more traditional in their gender role attitudes were likely to endorse more positive attitudes toward males' use of psychological dating violence. For men, due to the small sample size, three separate regression analyses were run. The first included only the demographic predictor variables (current year at university and family income), the second included only the attitudinal predictor variables (role hierarchy and endorsement of cohabitation) and the third regression analysis included only the personal well-being predictor variables (shame and depression). No further regression analyses were conducted at this point 
because the independent variables did not significantly predict attitudes toward male perpetrated psychological dating violence. See Table 4. [Insert Table 4]

\section{Discussion}

The purpose of this study was to answer three main research questions: (1) Do male and female Mainland Chinese college students differ in their attitudes toward dating violence? (2) Do Mainland Chinese college students have more accepting attitudes of psychological and physical dating violence when perpetrated by women than when perpetrated by men? (3) How do various demographic, attitudinal, and personal well-being variables predict attitudes toward male and female dating violence in Mainland Chinese college students?

\section{Acceptance of Dating Violence}

For the first research question, our preliminary findings show that male and female Mainland Chinese college students in this sample generally do not differ on their attitudes toward dating violence. Attitudes toward male perpetrated psychological dating violence was the only one of the four dating violence variables where men and women in this sample differed, with men holding significantly more positive attitudes. The literature related to attitudes toward dating violence and gender is limited and mixed. Further complicating the picture is the lack of consistent use of standardized measures and different samples (e.g., high school students versus college students). Although there is limited data on attitudes toward dating violence in general, dating violence perpetration rates have been found to be relatively similar between men and women (Straus, 2004). Therefore, given the similarity in perpetration rates among this population and given the connection between dating violence attitudes and dating violence perpetration (Archer \& Graham-Kevan, 2003; Bookwala et al., 1992; Foshee et al., 2001; 
O'Keefe, 1997; Riggs \& O’Leary, 1996), it is conceivable that men and women would hold similar attitudes toward dating violence perpetration.

For our second research question, Mainland Chinese college students in this sample were significantly more likely to endorse accepting attitudes toward female perpetrated psychological and physical dating violence than they were to endorse accepting attitudes toward male perpetrated psychological and physical dating violence. These results are consistent with previous qualitative literature focused on Mainland Chinese samples (Wang \& Sik Ying Ho, 2007).

\section{Predictors of Acceptance of Dating Violence}

Several factors, including shame, role hierarchy, endorsement of cohabitation, current year at university, and family income predicted attitudes toward dating violence. For Mainland Chinese college students in our sample, higher levels of perceived shame were associated with more accepting attitudes toward male and female perpetrated physical violence and female perpetrated psychological violence. Shame is an important concept in understanding the Chinese cultural and social context (Bedford, 2004; Qian, 2007). In Chinese society there is enormous pressure to conform to social norms and individuals tend to invest a greater proportion of selfidentity into relationships with other people in order to fit in to the society (Hwang, 1999; Stipek, Weiner, \& Li, 1989; Triandis, Bontempo, Villareal, Asai, \& Lucca, 1988). Our findings extend previous research (Harper et al., 2005) by showing that higher levels of shame are related to dating violence attitudes. Previous research would suggest a mechanism whereby shame is associated with anger and hostility directed outward, often toward those deemed responsible for contributing to the individual's feelings of shame, thereby increasing the chance that this outward aggression would be in the form of psychological and physical violence (Tangney, 1995; 
Wiginton et al. 2004). Scheff (1987) has even proposed a shame-rage spiral which involves an individual raging, consequently feeling ashamed, and then returning to rage to avoid the shameful feelings. Although we cannot directly test this mechanism in the current study, our study does point to a possible important link between shame and attitudes toward dating violence. Future studies could include anger and hostility as mediating factors between the shame/dating violence attitudes link (Harper et al.). Additionally, future studies could investigate how generalized feelings of shame or shame specific to the relationship, influences dating violence attitudes and behaviors. Given the salience of shame in Chinese culture, this would be an important area to investigate further.

For women, role hierarchy or having more traditional gender role attitudes was related to more accepting attitudes toward male perpetrated psychological dating violence. This finding is consistent with a variety of studies that have shown that acceptance of more traditional gender roles tends to be a predisposing factor toward more acceptance (Davis \& Liddell, 2002; Wade \& Brittan-Powell, 2001) and increased acts of dating violence in the United States (Parrot \& Zeichner, 2003; Reidy et al., 2009). Current research on attitudes toward women in China has revealed a gradual shift from more traditional gender role attitudes to a greater desire for equality in marital relationships by both Chinese men and women (Chia, Allred, \& Jerzak, 1997). Nevertheless, gender roles in China remain more conservative than those in the United States and Great Britain (Sun, Horn, \& Merritt, 2004). The current study builds on these previous studies by showing that the link between traditional gender role attitudes and attitudes toward dating violence is relevant among female Mainland Chinese college students. It could be assumed that women who hold more traditional gender attitudes and who view men as having more authority and power in the relationship are more likely to view male perpetrated 
psychological violence in a relationship as normal and therefore less likely to take action to combat it in their relationship.

In addition to shame and traditional gender role attitudes, current year at university, endorsement of cohabitation, and family income were related to dating violence attitudes. Specifically, current year at university was significantly related to greater acceptance of female perpetrated psychological dating violence and trended toward significance $(p<.10)$ for greater acceptance of male perpetrated physical dating violence. There is some evidence to suggest that college students, more so than other age groups, are more accepting of abusive behavior toward partners (Carlson, 1999). Research has consistently found that acceptance toward domestic violence decreases with age (Simon et al., 2001; Straus et al., 1997), but this has not been specifically studied within college student populations. Therefore, these results need to be replicated in order to confirm the salience of university year (i.e., grade) and attitudes toward dating violence. Finally, lower family income and endorsement of cohabitation were related to more accepting attitudes toward female physical dating violence (lower family income only marginally, $p<.10)$. In their study of college students, Nabors et al., (2006) did not find a link between family income and dating violence attitudes. Further, the literature on income and attitudes toward domestic violence is mixed (Simon et al., 2001; Straus et al., 1997). Given the fact that this link was only found for female perpetrated physical dating violence and that lower family income only marginally predicted attitudes toward female perpetrated physical dating violence (although the correlation was significant), currently this link can only be seen as tenuous at best. But, given the significant correlation this link does merit future investigation. Finally, we could find no other studies linking endorsement of cohabitation and dating violence attitudes. In the correlation analyses, endorsement of cohabitation was correlated with three of 
the four dating violence variables. Given that cohabitation is still relatively taboo in China (though like divorce and pre-marital sexual involvement, increasing dramatically) it may be that individuals more likely to support one non-mainstream belief (i.e., cohabitation is good) may also hold another (i.e., certain types of dating violence is okay). It could also be that individuals who are more accepting of dating violence also see relationships as more risky and therefore are more likely to believe that one must test out the relationship by living together first. Like the results related to current year in university, the results linking lower family income and endorsement of cohabitation with dating violence attitudes needs to be replicated before an affirmative link can be made.

\section{Limitations}

There are several limitations to this study. First, our sample was composed of Mainland Chinese college students from a single university. This constitutes a unique group within China, as the vast majority of college age individuals in China do not attend college. Second, over twothirds of our sample were women, thus limiting our ability to effectively compare predictors of dating violence attitudes separately for men and women. Third, some of our measures had adequate, but less than ideal reliability scores. Finally, given the variables in our dataset, we were unable to determine whether several known predictors of dating violence behavior such as alcohol use, witnessing parental violence, and increased negativity in the relationship also predicted dating violence attitudes in our sample. Despite these limitations, our exploratory study was an initial effort to identify some of the predictors of dating violence attitudes among Mainland Chinese college students. The strengths of this study include a relatively large sample size, the use of a standardized dating violence attitude measure, the inclusion of several known predictors of dating violence in our correlation (gender, relationship length, satisfaction with 
school performance) and regression analyses (depression, role hierarchy, family income) and the inclusion of a relevant cultural variable, shame, that provides a potentially important predictor to include in future studies related to dating violence attitudes and behaviors among intimate partners in China.

\section{Conclusion}

Relatively little is known about dating violence attitudes among young people in Mainland China. The results of this study show that among our sample of Chinese college students, men and women were relatively similar in their attitudes toward dating violence. As has been found in previous research in U.S. samples, men and women were more accepting of female perpetrated physical and psychological dating violence than male perpetrated physical and psychological dating violence. Finally, among several variables that predicted dating violence attitudes, shame emerged as a potentially important variable to include in future studies on dating violence in Chinese populations. 


\section{References}

Amar, A. F., \& Alexy, E. M. (2005). “Dissed” by dating violence. Perspectives in Psychiatric Care, 41(4), 162-171.

Amar, A. F., \& Gennaro, S. (2005). Dating violence in college women: Associated physical injury, healthcare usage, and mental health symptoms. Nursing Research, 54(4), 235-242.

Andrews, B., Qian, M., \& Valentine, J. D. (2002). Predicting depressive symptoms with a new measure of shame: The experience of shame scale. British Journal of Clinical Psychology, $41,29-42$.

Archer, J., \& Graham-Kevan, N. (2003). Do beliefs about aggression predict physical aggression to partners? Aggressive Behavior, 29, 41-54.

Baker, C. R., \& Stith, S. M. (2008). Factors predicting dating violence perpetration among male and female college students. Journal of Aggression, Maltreatment \& Trauma, 17, 227 244.

Banyard, V. L., \& Cross, C. (2008). Consequences of teen dating violence: Understanding intervening variables in ecological context. Violence Against Women, 14(9), 998-1013.

Bedford, O. A. (2004). The individual experience of guilt and shame in Chinese Culture. Culture Psychology, 10, 29-52.

Bethke, T. M., \& DeJoy, D. M. (1993). An experimental study of factors influencing the acceptability of dating violence. Journal of Interpersonal Violence, 8, 36-51.

Bookwala, J., Frieze, I. H., Smith, C., \& Ryan, K. (1992). Predictors of dating violence: A multivariate analysis. Violence and Victims, 7(4), 297-311.

Carlson, B. E. (1999). Student judgments about dating violence: A factorial vignette analysis. Research in Higher Education, 40, 201-220. 
Carmines, E. G., \& Zeller, R. A. (1979). Reliability and validity assessment. Beverly Hills: Sage.

Chan, K. L. (2009). Sexual violence against women and children in Chinese societies. Trauma Violence Abuse, 10, 60-85.

Chan, K. L., Straus, M. A., Brownridge, D. A., Tiwari, A., \& Leung, W. C. (2008). Prevalence of dating partner violence and suicidal ideation among male and female university students worldwide. Journal of Midwifery \& Women's Health, 53, 529-537.

Chan, K. L., Tiwari, A., Leung, W. C., Ho, H. W. Y., \& Cerulli, C. (2007). Common correlates of suicidal ideation and physical assault among male and female university students in Hong Kong. Violence and Victims, 22, 290-303.

Chase, K. A., Treboux, D., \& O'Leary, K. D. (2002). Characteristics of high-risk adolescents' dating violence. Journal of Interpersonal Violence, 17(1), 33-49.

Chen, P. H., \& White, H. R. (2004). Gender differences in adolescent and young adult predictors of later intimate partner violence. Violence Against Women, 10(11), 1283-1301.

Chia, R. C., Allred, L. J., \& Jerzak, P. A. (1997). Attitudes toward women in Taiwan and China: Current status, problems, and suggestions for future research. Psychology of Women Quarterly, 21, 137-150.

Davis, T. L. \& Liddell, D. L. (2002). Getting inside the house: The effectiveness of a rape prevention program for college fraternity men. Journal of College Student Development, 43, 35-50.

DeKeseredy, W., \& Kelly, K. (1993). The incidence and prevalence of woman abuse in Canadian university and college dating relationships. The Canadian Journal of Sociology, $18(2), 137-159$ 
Flood, M., \& Pease, B. (2009). Factors influencing attitudes to violence against women. Trauma, Violence, \& Abuse, 10, 125-142.

Foshee, V. A., Linder, F., MacDougall, J. E., \& Bangdiwala, S. (2001). Gender differences in the longitudinal predictors of adolescent dating violence. Preventative Medicine, 32, 128-141.

Hall, S. S. (2006). Marital meaning: Exploring young adults' belief systems about marriage. Journal of Family Issues, 27, 1437-1458.

Harper, F. W. K., Austin, A. G., Cercone, J. J., \& Arias, I. (2005). The role of shame, anger, and affect regulation in men's perpetration of psychological abuse in dating relationships. Journal of Interpersonal Violence, 20(12), 1648-1662.

Hwang, K.K. (1999). Filial piety and loyalty: The types of social identification in Confucianism. Asian Journal of Social Psychology, 2, 129-149.

Hwang, K.K. (2001). The deep structure of Confucianism: A social psychological approach. Asian Philosophy, 11(3), 179-204.

Josephson, W. L. \& Prouix, J. B. (2008). Violence in young adolescents' relationships: A path model. Journal of Interpersonal Violence, 23, 189-208.

Kroenke, K., Spitzer, R. L., \& Williams, J. B. W. (2001). The PHQ-9: Validity of a brief depression severity measure. Journal of General Internal Medicine, 16, 606-613.

Lester, D. (1997). The role of shame in suicide. Suicide and Life-Threatening Behavior, 27, 352361.

Lewis, H. B. (1971). Shame and guilt in neurosis. New York: International Universities Press.

Lewis, S. F., \& Fremouw, W. (2001). Dating violence: A critical review of the literature. Clinical Psychology Review, 21(1), 105-127. 
Luthra, R., \& Gidycz, C. A. (2006). Dating violence among college men and women: Evaluation of a theoretical model. Journal of Interpersonal Violence, 21(6), 717-731.

Marcus, R. F., \& Swett, B. (2002). Violence and intimacy in close relationships. Journal of Interpersonal Violence, 17, 570-586.

Medeiros, R. A., \& Straus, M. A. (2006). Risk factors for physical violence between dating partners : Implications for gender-inclusive prevention and treatment of family violence. In J. Hamel \& T. Nicholls (Eds.), Family Approaches in Domestic Violence : A Practitioner's Guide to Gender-Inclusive Research and Treatment (59-85). New York : Springer Publishing Company.

Murray, C. E., \& Kardatzke, K. N. (2007). Dating violence among college students : Key issues for college counselors. Journal of College Counseling, 10, 79-89.

Nabors, E. L., Dietz, T. L., \& Jasinski, J. L. (2006). Domestic violence beliefs and perceptions among college students. Violence and Victims, 21(6), 779-795.

O’Keefe, M. (1997). Predictors of dating violence among high school students. Journal of Interpersonal Violence, 12, 546-568.

O’Keefe, M. (1998). Factors Mediating the Link Between Witnessing Interparental Violence and Dating Violence. Journal of Family Violence, 13, 39-57.

O'Leary, K. D. \& Cascardi, M. (1998). Physical aggression in marriage: A developmental analysis. In T. N. Bradbury (Ed.). The developmental course of marital dysfunction (pp. 343-374). Cambridge University Press.

Parrot, D. J. \& Zeichner, A. (2003). Effects of hypermasculinity on physical aggression against women. Psychology of Men and Masculinity, 4, 70-78. 
Pettit, J. W., Lam, A. G., Volez, Z, R., Walker, R. L., Perez, M., Joiner, T. E. Jr., Lester, D., \& He, Z, X. (2002). Perceived burdensomeness and lethality of suicide method among suicide completers in the People's Republic of China. Omega, 45, 57-67.

Price, E. L., Byers, E. S., \& Dating Violence Research Team. (1999). The attitudes towards dating violence scales: Development and initial validation. Journal of Family Violence, $14(4), 351-375$.

Qian, M. (2007, October). Shame researches in mainland China. World Cultural Psychiatry Research Review, 113-136.

Qian, M., Andrews, B., Zhu, R., \& Wang, A. (2000). The development of the shame scale for Chinese college students. Chinese Mental Health Journal, 14, 217-221.

Reidy, D. E., Shirk, S. D., Sloan, C. A., \& Zeichner, A. (2009). Men who aggress against women: Effects of gender role violation on physical aggression in hypermasculine men. Psychology of Men and Masculinity, 10 (1), 1-12.

Riggs, D. S., \& O’Leary, K. D. (1996). Aggression between heterosexual dating partners: An examination of a causal model of courtship aggression. Journal of Interpersonal Violence, $11,519-540$.

Scheff, T. J. (1987). The shame-rage spiral: A case study of an interminable quarrel. In H. B. Lewis (Ed.), The Role of Shame in Symptom Formation (pp. 109-149). Hillsdale, NJ: Lawrence Erlbaum Associates.

Schwartz, J. P., Griffin, L. D., Russell, M. M., \& Frontaura-Duck, S. (2006). Prevention of dating violence on college campuses: An innovative program. Journal of College Counseling, 9, 90-96. 
Simon, T. R., Anderson, M., Thompson, M. P., Crosby, A. E., Shelley, G., \& Sacks, J. J. (2001). Attitudinal acceptance of intimate partner violence among U.S. adults. Violence and Victims, 16, 115-126.

Stipek, D., Weiner, B., \& Li, K. (1989). Testing some attribution-emotion relations in the People's Republic of China. Journal of Personality and Social Psychology, 56, 109-117.

Straus, M. A. (2008). Dominance and symmetry in partner violence by male and female university students in 32 nations. Children and Youth Services Review, 30, 252-275.

Straus, M.A. (2004). Prevalence of violence against dating partners by male and female university students worldwide. Violence Against Women, 10, 790-811.

Straus, M. A., Kantor, G. K., \& Moore, D. W. (1997). Change in cultural norms approving marital violence from 1968 to 1994. Out of Darkness: Contemporary Perspectives on Family Violence (3-16). Thousand Oaks, CA: Sage Publications, Inc.

Sun, T., Horn, M., \& Merritt, D. (2004). Values and lifestyles of individualists and collectivists: A study on Chinese, Japanese, British and US consumers. Journal of Consumer Marketing, 21(5), 318-331.

Tangney, J. P. (1995). Shame and guilt in interpersonal relationships. In J. P. Tangney \& K. W. Fischer (Eds.), Self-conscious emotions: Shame, guilt, embarrassment, and pride (pp. 114-139). New York: Guilford.

Tangney, J. P., Miller, R. S., Flicker, L., \& Barlow, D. H. (1996). Are shame, guilt, and embarrassment distinct emotions? Journal of Personality and Social Psychology, 70, 1256-1269. 
Triandis, H.C., Bontempo, R., Villareal, M.J., Asai, M., \& Lucca, N. (1988). Individualism and collectivism: Cross-culture perspectives on self-in-group relationships. Journal of Personality and Social Psychology, 54, 353-338.

Wade, J. C. \& Brittan-Powell, C. (2001). Men's attitudes toward race and gender equity: The importance of masculine ideology, gender-related traits, and reference group identity dependence. Psychology of Men and Masculinity, 2, 42-50.

Wang, X. \& Sik Ying Ho, P. (2007). My sassy girl: A qualitative study of women's aggression in dating relationships in Beijing. Journal of Interpersonal Violence, 22, 623-638.

Wiginton, K., Rhea, D. J., \& Oomen, J. (2004). Using the anger response inventory to evaluate the effect of shame and guilt. American Journal of Health Education, 35(3), 152-157. 
Table 1. Zero-Order Correlations Between the Four Attitudes Towards Dating Violence Scales and the Six Independent Variables

\begin{tabular}{|c|c|c|c|c|c|c|c|c|c|c|c|}
\hline Variable & 1 & 2 & 3 & 4 & 5 & 6 & 7 & 8 & 9 & 10 & 11 \\
\hline 1. Male Psychological & $\begin{array}{c}--- \\
\end{array}$ & & & & & & & & & & \\
\hline 2. Male Physical & $.39 * *$ & ---- & & & & & & & & & \\
\hline 3. Female Psychological & $.46^{* *}$ & $.38 * *$ & ---- & & & & & & & & \\
\hline 4. Female Physical & $.28 * *$ & $.49 * *$ & $.48 * *$ & ---- & & & & & & & \\
\hline 5. Shame & $.16^{*}$ & $.20 * *$ & $.18 * *$ & .09 & ---- & & & & & & \\
\hline 6. Depression & $.13^{*}$ & .08 & $.11 \dagger$ & .00 & $.48 * *$ & ---- & & & & & \\
\hline 7. Role Hierarchy & $.24 * *$ & .07 & $.17 * *$ & $.12 \dagger$ & $.14^{*}$ & .03 & ---- & & & & \\
\hline 9. Year at University & .10 & .10 & $.22 * *$ & .07 & .02 & -.01 & $-.14^{*}$ & .01 & ---- & & \\
\hline 10. Family Income & .07 & -.11 & -.06 & $-.16^{*}$ & -.08 & -.08 & $-.13 \dagger$ & $-.15^{*}$ & .11 & ---- & \\
\hline 11. Cohabitation & .09 & $.15^{*}$ & $.12 \dagger$ & $.19 * *$ & .00 & .00 & .00 & .04 & .05 & $-.13 \dagger$ & --- \\
\hline
\end{tabular}


Table 2

Comparison of Mean Differences Between Male and Female Attitudes Toward Dating Violence

\begin{tabular}{|c|c|c|c|c|c|c|c|}
\hline \multirow[b]{2}{*}{ Variables } & \multirow[b]{2}{*}{$n$} & \multicolumn{2}{|c|}{ Men } & \multirow[b]{2}{*}{$n$} & \multicolumn{2}{|c|}{ Women } & \multirow[b]{2}{*}{$F$} \\
\hline & & $M$ & $(S D)$ & & $M$ & $(S D)$ & \\
\hline \multicolumn{8}{|l|}{ Dependent Variables } \\
\hline Female Physical & 49 & 33.31 & $(7.61)$ & 183 & 34.01 & $(7.03)$ & 0.376 \\
\hline Female Psychological & 52 & 34.58 & $(5.85)$ & 183 & 33.26 & $(7.01)$ & 1.527 \\
\hline Male Physical & 50 & 30.02 & $(7.11)$ & 179 & 30.21 & $(7.09)$ & 0.027 \\
\hline Male Psychological & 51 & 38.71 & $(6.17)$ & 179 & 36.24 & $(7.13)$ & $5.020 *$ \\
\hline \multicolumn{8}{|l|}{ Independent Variables } \\
\hline Shame & 49 & 55.35 & $(12.81)$ & 179 & 56.02 & (11.61) & 0.124 \\
\hline Depression & 54 & 7.11 & $(5.24)$ & 184 & 6.29 & $(4.30)$ & 1.362 \\
\hline Role Hierarchy & 54 & 8.30 & $(2.38)$ & 186 & 7.03 & $(2.00)$ & $15.431 * * *$ \\
\hline Yr. at University & 54 & 1.85 & $(.66)$ & 187 & 2.09 & $(.83)$ & 3.660 \\
\hline Family Income & 51 & 2829 & $(3141)$ & 159 & 3592 & $(3687)$ & 1.768 \\
\hline Cohabitation & 54 & 15.57 & $(3.87)$ & 184 & 14.49 & $(3.55)$ & 3.742 \\
\hline
\end{tabular}


Table 3

Multiple Regression Analysis Results for Variables Predicting Attitudes Toward Female

Physical and Female Psychological Dating Violence $(N=192)$

\begin{tabular}{|c|c|c|c|c|c|c|}
\hline \multirow[t]{2}{*}{ Variable } & \multicolumn{3}{|c|}{ Female Physical } & \multicolumn{3}{|c|}{ Female Psychological } \\
\hline & $B$ & $S E B$ & $\beta$ & $B$ & $S E B$ & $\beta$ \\
\hline Shame & .100 & .050 & $.159 *$ & .105 & .046 & $.177^{*}$ \\
\hline Depression & -.082 & .122 & -.053 & .096 & .112 & .066 \\
\hline Role Hierarchy & .164 & .237 & .051 & .291 & .216 & .095 \\
\hline Year at University & .449 & .663 & .051 & 1.913 & .606 & $.219 * *$ \\
\hline Family Income & .000 & .000 & $-.125 \dagger$ & .000 & .000 & -.040 \\
\hline Endorsement & .284 & .141 & $.144^{*}$ & .162 & .127 & .089 \\
\hline \multicolumn{7}{|l|}{ of Cohabitation } \\
\hline Constant & 23.557 & 3.782 & ---- & 19.197 & 3.446 & ---- \\
\hline$F$ & $2.466^{*}$ & & & $4.432 * *$ & & \\
\hline $\mathrm{R}^{2}$ & .074 & & & .124 & & \\
\hline
\end{tabular}


Table 4

Multiple Regression Analysis Results for Variables Predicting Attitudes Toward Male Physical and Male Psychological Dating Violence $(N=190 / 144)$

\begin{tabular}{|c|c|c|c|c|c|c|}
\hline \multirow[t]{2}{*}{ Variable } & \multicolumn{3}{|c|}{ Male Physical } & \multicolumn{3}{|c|}{ Male Psychological $^{\mathrm{a}}$} \\
\hline & $B$ & $S E B$ & $\beta$ & $B$ & SE B & $\beta$ \\
\hline Shame & .122 & .050 & $.197 *$ & .050 & .060 & .078 \\
\hline Depression & -.031 & .120 & -.021 & .099 & .148 & .062 \\
\hline Role Hierarchy & .010 & .232 & .003 & .753 & .283 & $.221 * *$ \\
\hline Year at University & 1.245 & .654 & $.137 \dagger$ & .883 & .730 & .100 \\
\hline Family Income & .000 & .000 & -.090 & .000 & .000 & -.028 \\
\hline Endorsement & .198 & .137 & .104 & .055 & .166 & .028 \\
\hline \multicolumn{7}{|l|}{ of Cohabitation } \\
\hline Constant & 18.667 & 3.715 & ---- & 25.236 & 4.338 & ---- \\
\hline$F$ & $2.638^{*}$ & & & $2.176^{*}$ & & \\
\hline $\mathrm{R}^{2}$ & .079 & & & .086 & & \\
\hline
\end{tabular}

Note: ${ }^{a}$ Results predicting female attitudes toward male psychological dating violence. Results predicting male attitudes toward male psychological dating violence not shown.

$\dagger p<.10 .{ }^{*} p<.05 . * * p<.01 . * * * p<.001$ 